\title{
Advanced Medical Thoracoscopy
}

\author{
G.F. Tassi1, G.P. Marchetti1, P.L. Aliprandi2
}

Monaldi Arch Chest Dis 2011; 75: 1, 99-101.

Keywords: Parapneumonic pleural effusion, Pleural empyema, Medical thoracoscopy, Video-assisted thoracoscopic surgery (VATS), Thoracoscopic lung biopsy.

1 Divisione di Pneumologia, Spedali Civili di Brescia,

2 U.O. Medicina III, Pneumologia Interventistica, Ospedale di Rho, A.O.G. Salvini, Garbagnate Milanese (Milano), Italy.

Correspondence: Dr. G.F. Tassi, Divisione di Pneumologia, Spedali Civili di Brescia, Piazzale Spedali Civili 1, 25123 Brescia, Italy; e-mailgf.tassi@tin.it

Advanced medical thoracoscopy include the less frequent and more complex applications of medical thoracoscopy: 1) the management of parapneumonic pleural effusion and pleural empyema; 2) the thoracoscopic lung biopsy; 3) the thoracoscopic simpathectomy [1]. They can considered as non-routine methods and represent the areas of application of medical thoracoscopy for expert pulmonologists. They can also be an aim for those who, having learned and applied the basic techniques, want to develop them further.

\section{Thoracoscopy}

For years, thoracoscopy has largely been used in pleural effusion due to lung infection, as an alternative to thoracotomy, because it allows the mechanical removal of infected material and permits lung re-expansion. It is possible to open multiple loculations and aspirate the purulent liquid, removing the fibrinous adhesions, including the layer on visceral pleura. Therefore, it is possible to have a single cavity in which, using an accurately positioned chest tube, subsequent local treatment is facilitated with antiseptic solutions or fibrinolytics. Moreover, the possibility to perform pleural biopsies allows the precise aetiological definition of the disease and aids the diagnosis of occult infections (e.g. tuberculosis) or tumours causing pleural effusion. Most thoracoscopic empyema treatments are performed and described by surgeons using classical three-entry port intervention under general anaesthesia and double-lumen intubation [1]. However, it is important to remember that thoracoscopy in empyema may also be performed by expert medical thoracoscopists [25]. However, the exact application of thoracoscopy in infections of the pleural cavity has yet to be established universally. Its use has been proposed prior to the positioning of a thoracic drain, while another application might be only after the drain has not determined a reduction in temperature or the complete evacuation of pleural fluid within a few days. Yet another approach makes reference to the loculate character of the effusion, and considers thoracoscopy appropriate in the presence of loculated empyema. More recently, in the surgical field the treatment has been extended to chronic organising empyema, both to clean the cavity prior to thoracotomic decortication, and for the actual decortication [1]. The case studies of the role of thoracoscopy in the infection of the pleural space deal principally with empyema and are both medical and surgical, the latter being undoubtedly more numerous [6]. In general the figures demonstrate favourable results, with percentages of primary success (meaning complete cure without subsequent thoracotomy or video-assisted thoracoscopic surgery (VATS), or conversion from VATS to thoracotomy) between $60 \%$ and $100 \%$, and higher if the method was used without delay. However the number of patients treated was generally small, and few authors present case studies dealing with more than 100 patients.

In surgical thoracoscopy there is total agreement about the advantages of VATS over thoracotomy, in terms of lower cost, shorter hospitalisation, and better cosmetic results with less surgical sequelae. The medical thoracoscopy experiences outline the mini-invasive character of the procedure, together with lower cost compared to VATS and the fact that it can be used with frail patients at high risk from surgery.

Complications occurred in direct correlation with the complexity of the cases treated and were represented mainly by prolonged air leakage and bleeding, with very varied incidence, between $16 \%$ and $0 \%$ [1]. In some surgical series, including patients with severe comorbidity, deaths also occured.

Therefore thoracoscopy is undoubtedly useful in the treatment of infection of the pleural space, in particular with multiloculate empyema, since it permits the treatment of the illness without thoracotomy, even though until now sufficiently large randomised studies on the method have not been carried out. As an intermediate drain procedure between positioning a drain tube and VATS, medical thoracoscopy can play an important role and is characterised by its efficacy and low cost. It should be carried out without delay in the treatment of empyema and is recommended for patients in poor health and at high surgical risk. 


\section{Recommendations}

- Thoracoscopy is indicated in loculated parapneumonic effusion and empyema (Grade B).

- Chest ultrasonography is the method of choice to identify loculations (Grade C).

- Medical thoracoscopy, as a drainage procedure which is intermediate between tube thoracostomy and VATS, is significantly lower in cost and can avoid surgical thoracoscopy under general anaesthesia (Grade $\mathbf{C}$ ).

- It is essential that medical thoracoscopy is performed early in the course of empyema and advisable in particular for frail patients at high surgical risk (Grade C).

\section{References}

1. Tassi GF, Davies RJ, Noppen M. Advanced techniques in medical thoracoscopy. Eur Respir J 2006; 28: 10511059.

2. Colt HG. Thoracoscopy. A prospective study of safety and outcome. Chest 1995; 108: 324-329.

3. Solèr M, Wyser C, Bolliger CT, Perruchoud AP. Treatment of early parapneumonic empyema by "medical" thoracoscopy. Schweiz Med Wochenschr 1997; 127: 1748-1753.

4. Reynard C, Frey JG, Tschopp JM. Thoracoscopie en anesthésie locale dans le traitement des empyèmes: une technique efficace et peu invasive. Med Hyg 2004; 62: 2138-2143

5. Brutsche MH, Tassi GF, Gjörik S, et al. Treatment of sonographically stratified multiloculated thoracic empyema by medical thoracoscopy. Chest 2005; 128 : 3303-309.

6. Waller DA.Thoracoscopy in management of postpneumonic pleural infections. Curr Opin Pulm Med 2002; 8: 323-326.

\section{Thoracoscopic Lung biopsy}

Forceps lung biopsy during thoracoscopy under local anaesthesia has been used for many years by pulmonologists and has been described frequently as an integral technique of medical thoracoscopy [7-11]. With the advent of videoassisted thoracoscopic surgery (VATS) its employment has been considerably reduced in particular in lung nodules and in diffuse lung disease. However the biopsy of visceral pleura and lung in patients with pleural effusion and visceral pleura involvement or associated lung disease (mesothelioma; metastatic tumour; suspected carcinomatous lymphangitis; suspected asbestosis) still maintains its importance and significance. In particular, in mesothelioma, the identification of visceral pleura involvement by biopsy is crucial to establish the stage of development of the disease [12].

\section{Recommendation}

- Thoracoscopic forceps lung biopsy is indicated in in patients with pleural effusion and associated lung disease (Grade C) Thoracoscopic forceps lung biopsy is indicated to evaluate the visceral pleura involvement in mesothelioma (Grade C).

\section{References}

7. Boutin C, Viallat JR, Aelony Y (1991). Practical thoracoscopy. Springer, Berlin Heidelberg New York.

8. Mathur PN, Loddenkemper R. Medical thoracoscopy. Role in pleural and lung diseases. Clin Chest Med 1995; 16: 487-496.

9. Mathur PN, Astoul P, Boutin C. Medical thoracoscopy. Technical details. Clin Chest Med 1995; 16: 479-486.

10. Loddenkemper R. Thoracoscopy - state of the art. Eur Respir J 1998; 11: 213-221.

11. Vansteenkiste J, Verbeken E, Thomeer M, Van Haecke P, Eeckhout AV, Demedts M. Medical thoracoscopic lung biopsy in interstitial lung disease: a prospective study of biopsy quality. Eur Respir J 1999; 14: 585-590.

12. Arnaud Scherpereel, French Speaking Society for Chest Medicine (SPLF). Guidelines of the French Speaking Society for Chest Medicine for management of malignant pleural mesothelioma. Respir Med 2007; 101: $1265-1276$.

\section{Sympathectomy}

Thoracoscopic sympathectomy, the anatomical interruption of the thoracic sympathetic chain by means of thoracoscopic techniques, more frequently performed and described by surgeons, can safely be performed by trained interventional pulmonologists [13-18]. It is a minimally invasive, accepted intervention for patients with a variety of autonomous nervous system disturbances with short- and long-term excellent results. It should be carried out by expert and highly trained thoracoscopists [19] and carried out in specialized centres with sufficient expertise in close collaboration with thoracic surgeons.

\section{Recommendations}

- Thoracoscopic can be performed safely by trained interventional pulmonologists (Grade C).

- Thoracoscopic sympathectomy carried out in specialised centres with sufficient expertise in close collaboration with thoracic surgeons (Grade C).

\section{References}

13. Noppen M, Herregodts P, D’Haese J, D’Haens J, Vincken W. A simplified T2-T3 sympathicolysis technique for the treatment of essential hyperhidrosis: short-term results in 100 patients. J Laparoendosc Surg 1996; 6: 151-159. 
14. Hashmonai M, Assalia A, Kopelman D. Thoracoscopic sympathectomy for palmar hiperhydrosis. Ablate or resect? Surg Endosc 2001; 15: 435-441.

15. Goh PMY, Cheah WK, DaCosta M, Sin EKW. Needlescopic thoracic sympathectomy: treatment for palmar hyperhidrosis. Ann Thorac Surg 2000; 70: 240-242.

16. Atkinson JL, Fealy RD. Sympathicotomy instead of sympathectomy for palmar hyperhidrosis: minimizing postoperative compensatory hyperhidrosis. Mayo Clin Proced 2003; 78: 167-172.

17. Noppen M. Medical thoracoscopy. Techniques for thoracic sympathectomy. In: Beamis JF, Mathur PN, Mehta $\mathrm{AC}$, eds. Interventional pulmonary medicine. Marcel Dekker, New York, 2004; pp. 483-502.

18. Guerin JC, Boutin C. Thoracoscopie médicale interventionnelle. Rev Mal Respir 1999; 16: 703-708.

Summary of Recommendations

- Thoracoscopy is indicated in loculated parapneumonic effusion and empyema (Grade B).

- Chest ultrasonography is the method of choice to identify loculations (Grade C).

- Medical thoracoscopy, as a drainage procedure which is intermediate be- tween tube thoracostomy and VATS, is significantly lower in cost and can avoid surgical thoracoscopy under general anaesthesia (Grade C).

- It is essential that medical thoracoscopy is performed early in the course of empyema and advisable in particular for frail patients at high surgical risk (Grade C).

- Thoracoscopic forceps lung biopsy is indicated in in patients with pleural effusion and associated lung disease (Grade C).

- Thoracoscopic forceps lung biopsy is indicated to evaluate the visceral pleura involvement in mesothelioma (Grade C).

- Thoracoscopic can safely be performed by trained interventional pulmonologists (Grade C).

- Thoracoscopic sympathectomy carried out in specialised centres with sufficient expertise in close collaboration with thoracic surgeons (Grade C).

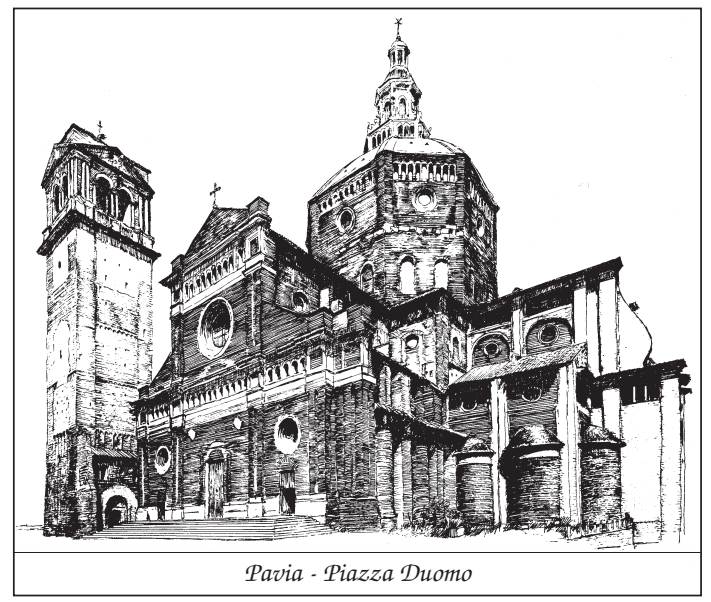

